\section{Experiential Education Employed to Demystify Food Irradiation as a Viable Technology for Food Industry Professionals}

\author{
Janet Laminack ${ }^{1}$, Frank Dainello ${ }^{2}$, Tom A. Vestal ${ }^{3}$, and \\ Gary Wingenbach ${ }^{4}$
}

\begin{abstract}
ADDITIONAL INDEX WORDS. foodborne, food safety
SUMMARY. Research shows that food irradiation is a safe food technology effective in reducing pathogenic microorganisms, prolonging shelf life, and controlling pests, such as mediterranean fruit fly (Ceratitis capitata), to avoid quarantine. The purpose of this research was to study the effectiveness of a professional development program designed with a variety of experiential education strategies targeting food industry regulators, extension agents, and others in the food industry. A short course employed experiential education components, such as presentations by experts in food irradiation technology, tours of food irradiation facilities, group activities, and a taste-test of irradiated produce and meat. Data were collected that assessed participants' knowledge, perceptions, and concerns about food safety and food irradiation, using Likert-type scales. The short course produced significant knowledge gains. Respondents' perceptions of food safety and food irradiation issues were improved significantly as a result of participation in the short course. Also, respondents' perceived knowledge and understanding of food safety, food irradiation, and the technology behind food irradiation improved significantly upon completion of the short course.
\end{abstract}

$\mathrm{T}$ he concept of using irradiation to destroy bacteria and to improve food safety has existed for a century. Simply put, the treatment of food by exposure to low energy ionizing radiation is food irradiation (Park and Vestal, 2003). In 1905, the first patent was issued in Britain that proposed killing bacteria in food using irradiation (Andress, 2001; Diehl, 2002). The U.S. Food and Drug Administration (FDA) approved irradiation for wheat (Triticum spp.) in 1963 for insect disinfestation; for potato (Solanum tuberosum) in 1964 to inhibit sprouting; and for shelflife extension of potatoes in 1965 (Andress, 2001; Ten Eyck, 2002). In 1970, the International Project in the

\footnotetext{
Extension Horticulture, Texas Cooperative Extension, Mail Stop 2134, Texas A\&M University, College Station, TX 77843-2134.

${ }^{1}$ Research Assistant.

${ }^{2}$ Professor and Extension Specialist.

${ }^{3}$ Associate Professor and Extension Specialist, Department of Agricultural Education, 119B Scoates Hall, Mail Stop 2116, Texas A\&M University, College Station, TX 77843

${ }^{4}$ Associate Professor, Department of Agricultural
} Education.
Field of Food Irradiation was created to investigate the safety of irradiated food for human consumption because of the slow rate of adoption as a result of a lack of adequate research (Diehl, 2002). The Joint Food and Agriculture Organization of the United Nations (FAO)/International Atomic Energy Agency (IAEA)/World Health Organization (WHO) Expert Committee on the Wholesomeness and Safety of Food Irradiation evaluated the results of the International Project and approved irradiation of several food items in 1976 (Diehl, 2002). In 1980, the Joint Expert Committee concluded that food irradiated up to a maximum dose of $10 \mathrm{kGy}$ presented no toxicological hazard and required no further testing (Andress, 2001; Diehl, 2002). An FAO/IAEA/WHO Study Group on High Dose Irradiation examined doses up to $70 \mathrm{kGy}$ and found no adverse health effects in long-term animal feeding studies, thus concluding in 1997 that any dose appropriate to achieve the treatment objective is both safe and maintains adequate nutritional content (Diehl, 2002). The three types of ionizing irradiation technologies are electron beams, $\mathrm{x}$-rays, and gamma rays (Park and Vestal, 2003). Electron beam irradiation is the only technology considered by this paper. Electron beam irradiation uses commercial electricity as an energy source and can be switched on or off, which differs from gamma ray technology (Park and Vestal, 2003).

Although research has shown that food irradiation is a safe food technology effective in reducing pathogenic microorganisms, prolonging shelf life and controlling pests, this technology has not been widely adopted. One possibility for this may be a lack of understanding on the part of food industry professionals about food irradiation. Sociological studies have shown that decisions about new foods and risk invoke intuitive and emotional behavior based on selective perception (Hoban, 1996; National Research Council, 1989). These studies point out that some consumers are skeptical of unfamiliar technologies particularly when the technology involves something so close and personal as how their food is produced (National Research Council, 1989).

Qualitative, rather than quantitative, behavior leads consumers to base decisions about food technology on feelings, rather than fact. Zimmerman, et al. (1994) suggest assessing whether consumer perceptions and beliefs are cognitive or affective when considering suitable educational messages about new food technologies. May (1969) states that perceptions about topics are based on past experience and knowledge, without which a person cannot accurately perceive the topic. Studies have shown that perceptions are often based on already present global attitudes toward similar topics or technologies when knowledge about the topic or technology is low (Fazio et al., 1989; Sanbonmatsu and Fazio, 1990).

Edwards (1990) found affective messages, rather than cognitive messages, were more useful in modifying affective-based attitudes. Studies indicate affective approaches are more successful when knowledge of the subject or issue at hand is low, which is often the case with food technologies (Edwards, 1990). Our study was conducted to determine if an experiential educational experience would positively influence knowledge gains of food irradiation, perceptions of food irradiation, and 
understanding of food safety among food industry professionals.

\section{Methods}

Purpose/goal. A short course was conducted to discuss the latest innovations and safety of electron beam technology to enhance food safety and phytosanitation of complex food items such as fruit and vegetables. The target audiences of this short course were those who would either apply this technology or influence another's adoption of the technology, such as vegetable producer processors and extension agents. Invitations to the course were sent to more than 160 individuals involved in some aspect of the produce industry in Texas.

Participants. The participants for this short course were employed in various professions ranging from retail grocery, food safety regulators, county extension educators, and produce importers. Total number of participants was 23: three were extension educators, one a food processor, one worked for a port authority, and 18 were food safety regulators.

The participants in this short course comprised a case study of 22 . Gall et al. (2003) defined a case study as an "in-depth study of instances of a phenomenon in its natural context and from the perspective of the participants involved in the phenomenon." Although 23 professionals voluntarily participated in the short course, usable paired data were gathered from 22 participants. One participant changed employment between the pre- and post-tests and was unable to provide usable post-test results. The participants consisted of 19 males and three females. Education levels were distributed fairly evenly, with seven holding doctorate degrees, three holding master's degrees, six with bachelor's degrees, and six with high school or equivalent degrees. One-half (11) of the respondents were $50-59$ years old at the time of the short course; six participants were 40-49 years old; and four participants were 30-39 years old. More than onehalf were Caucasian (12), while six were Hispanic American. The other four participants responded as multiracial, Asian American, Polynesian, and Indian. More than $70 \%$ of the respondents (16) had 11 or more years of professional experience in the food industry (departments of health, food inspectors, etc.) or Cooperative Extension Service. However, nearly one-half $(45.5 \%)$ had not communicated with clientele about food irradiation issues over the 12 months prior to the short course

The short COURSE. The short course, Improving Safety of Complex Food Items Using Electron Beam Technology, included presentations by experts in food irradiation technology, tours of food irradiation facilities, group discussions, and an irradiated produce and meat tasting. Topics included the use of irradiation for microbial safety in fresh-cut produce, phytosanitary applications of electron beam (e-beam) irradiation in fruit and vegetables, the use of irradiation to extend shelf life, and irradiation dosimetry for irregularly shaped products, such as whole fruit and vegetables. Topics also included addressing consumer concerns about and acceptance of irradiation; status of food irradiation around the world; comparison of quality, health, and nutritional properties of fresh fruit and vegetables pre- and post irradiation; and an analysis of the economics of food irradiation from the perspective of both the consumer and the producer.

LOgisTics AND EDUCATIONAL METHODS. The short course was held at the Institute of Food Science and Engineering on the Texas A\&M University campus in College Station. A key component was the tour of the Texas A\&M Electron Beam Food Research facility. The short course incorporated several experiential education elements such as irradiation facility and dosimetry lab tours, interaction with scientists and engineers, and taste testing of irradiated produce. Produce sampled included papaya (Carica papaya), cantaloupe (Cucumis melo), grape (Vitis vinifera), blackberry (Rubusspp.), and strawberry (Fragaria xananassa).

Experts in specific areas of food irradiation presented participants with the most current research findings available related to e-beam irradiation and its use. Participant feedback throughout the short course was solicited and incorporated. At the end of each day, participants' specific educational interests and needs were discussed in a round-table format. These discussions provided the most critical elements of educational needs, which were used to develop four educational modules to be available on compact disc and online, which will be pilot-tested in 2006 .

Research instrumentation. Likert-type scales (Likert, 1932) were used to collect the data. The paired short course pre- and post-tests assessed participants' perceptions, understanding, concerns, and knowledge about food safety and food irradiation. Cronbach's coefficient alpha was used to determine reliability of the scales (Cronbach, 1951). According to Gall et al. (2003), reliability studies provide information on the extent to which a measure produces similar results for the same subjects at different times or different conditions. Mehrens and Lehmann (1973) state that a coefficient alpha of 0.65 denotes a satisfactory level of internal consistency and reliability. Guidelines for levels of Cronbach's coefficient alpha state that a coefficient is adequate if it is from 0.60 to 0.79 and rated excellent if it is greater than 0.80 (Nunnally, 1976).

Perceptions about food safety AND FOOD IRRADIATION ISSUES. Respondents recorded their levels of agreement for 18 statements to measure perceptions about food safety and food irradiation issues. Responses ranged from strongly disagree (1) to strongly agree (4) on a four-point scale. The perceptions of food safety and food irradiation issues scale produced Cronbach's coefficient alpha of 0.85 in the pre-test and 0.91 in the post-test.

UNDERSTANDING OF FOOD SAFETY, FOOD IRRADIATION, AND FOOD IRRADIATION TECHNOLOGY. Respondents were asked to assess their overall understanding of food safety, food irradiation, and food irradiation technology. Responses could range from poor (1) to excellent (5) on a five-point scale; Cronbach's coefficient alpha for the understanding of food safety and food irradiation scale was 0.83 in the pre-test and 0.89 for the post-test.

LEVELS OF CONCERN FOR FOOD SAFETY ISSUES. Respondents ranked their overall concern, using a scale ranging from no concern (1) to highly concerned (10), for seven food safety issues. Cronbach's coefficient alpha for the food safety concerns scale was 0.90 in the pre-test and 0.87 in the post-test.

KNOWLEDGE OF FOOD IRRA- 
DIATION. Respondents assessed their knowledge of food irradiation by answering five multiple-choice (four possible choices) questions. Knowledge questions were created by the researchers from the instructional materials designed for the short course. Sample questions included: "Approved doses offood irradiation can: destroy bacteria; and, "Compared to cooked or frozen food, food that is irradiated at approved doses has: similar nutritional value." The Kuder-Richardson Formula 20 (Ary et al., 1996) was calculated on the summarized knowledge scale to determine scale reliability. The overall knowledge scale produced a reliability coefficient of 0.58 .

Data collection. The pre- and post-tests were administered via a secure Internet site (Wingenbach et al., 2004), where participants completed both tests as part of the short course. The online method was chosen for test delivery based on its ability to achieve fast, accurate response rates at minimal expense (Ladner et al., 2002). For those who were unfamiliar with the technology, assistance was provided on accessing the web page and completing the assessment.

Data analysis. Descriptive statistics (mean, SD, frequency) were used to describe respondents and data. Additional understanding of the impact from the Improving Safety of Complex
Food Items Using Electron Beam Technology short course was garnered from analyses of paired samples $t$-tests on the summarized scaled response sets for food safety and food irradiation: 1) knowledge, 2) perceptions, 3 ) understanding of technology, 4) concerns with safety issues, 5 ) perceived consumers' concerns, and 6) perceived major concerns affecting the adoption of irradiated foods.

Overall knowledge was derived from a possible perfect score of five correct responses. Participants' knowledge ranged from 2-5 correct responses in the pre-test, and $3-5$ in the post-test. Respondents' overall perceptions of food safety and food irradiation using four-point summarized scales for 18 items ranged from 41-69 in the pre-test, and 50-7l in the post-test. To determine respondents' overall understanding of food safety and food irradiation, five-point scales were added; the three items indicating understanding ranged from 4-15 in the pre-test, and $6-15$ in the post-test. To determine respondents' overall levels of concern in food safety issues, 10 -point scales were added together. Concern levels for seven items ranged from 14-67 in the pre-test, and 17-68 in the post-test. Ten-point scales were summarized to determine respondents' overall perceived consumer concerns with irradiated foods; perceived con- sumer concerns (six items) ranged from 22-60 in the pre-test, and 11-59 in the post-test. Four-point scales were summarized to determine respondents' overall perceived variables affecting adoption of irradiated foods; variables affecting adoption (five items) ranged from $11-16$ in the pre-test, and 12-15 in the post-test.

\section{Results and discussion}

Perceptions about food SAFety AND FOOD IRRADIATION ISSUES. Respondents recorded their levels of agreement for 18 statements to measure perceptions about food safety and food irradiation issues (Table 1). Respondents strongly agreed with the statement, "I am interested in learning more about food safety issues" in both the pre- and post-tests (mean $=3.83$ ) Respondents agreed more strongly with the following statements in the post-test than they did in the pre-test:

-Foodborne illness caused from bacteria on meats is a serious problem.

-Irradiation will improve the safety of food available to consumers.

-Foodborne illness caused from bacteria on fruit and vegetables is a serious problem.

-I feel scientifically confident about food irradiation.

Respondents disagreed with the

Table 1. Participants' perceptions $(n=22)$ of food safety and food irradiation statements from pre- and post-tests in the Improving Safety of Complex Food Items Using Electron Beam Technology short course, presented by descending post-test means.

\begin{tabular}{|c|c|c|c|c|}
\hline \multirow[b]{2}{*}{ Statements } & \multicolumn{2}{|c|}{ Pre-test } & \multicolumn{2}{|c|}{ Post-test } \\
\hline & Mean $^{\mathrm{z}}$ & SD & Mean $^{\mathrm{z}}$ & SD \\
\hline I am interested in learning more about food safety issues. & 3.83 & 0.39 & 3.83 & 0.39 \\
\hline Irradiation will improve the safety of food available to consumers. & 3.48 & 0.51 & 3.70 & 0.47 \\
\hline Food that has been irradiated is safe to eat. & 3.30 & 0.63 & 3.70 & 0.47 \\
\hline Foodborne illness caused from bacteria on fruit and vegetables is a serious problem. & 3.35 & 0.57 & 3.65 & 0.49 \\
\hline Food irradiation has been endorsed by the American Medical Assn. and American Dietetic Assn. & 2.86 & 0.56 & 3.48 & 0.67 \\
\hline I would buy irradiated food if it were available. & 3.26 & 0.54 & 3.41 & 0.73 \\
\hline I would serve irradiated foods to my family. & 3.22 & 0.74 & 3.39 & 0.72 \\
\hline I feel comfortable informing customers about food irradiation. & 2.86 & 0.77 & 3.35 & 0.65 \\
\hline I feel scientifically confident about food irradiation. & 2.95 & 0.86 & 3.26 & 0.54 \\
\hline Irradiated food causes cancer. & 1.68 & 0.65 & 1.27 & 0.46 \\
\hline Irradiation will make food radioactive. & 1.43 & 0.59 & 1.22 & 0.42 \\
\hline
\end{tabular}

${ }^{2}$ Likert-type scale: 1 = strongly disagree; 2 = disagree; 3 = agree; $4=$ strongly agree. 
following statements in the pre-test and disagreed more strongly with them in the post-test:

-Irradiation facilities give off radiation to the surrounding community.

- Irradiated food causes cancer.

- Irradiation will make food radioactive.

UNDERSTANDING OF FOOD SAFETY, FOOD IRRADIATION, AND FOOD IRRADIATION TECHNOLOGY. Respondents assessed their overall understanding of food safety, food irradiation, and food irradiation technology (Table 2). In the post-test, respondents rated themselves as having a "good" understanding ( mean $=4.09)$ of food safety, and "average" $($ mean $=3.74)$ understanding of food irradiation technologies and food irradiation $($ mean $=3.70)$. In the pre-test, the respondents had rated themselves as having a "fair" ( mean = 2.17) understanding of food irradiation technologies and food irradiation $($ mean $=2.35)$.

LEVELS OF CONCERN FOR FOOD SAFETY ISSUES. Respondents ranked their overall concern, using a scale that ranged from no concern (1) to highly concerned (10), for seven food safety issues (Table 3). Respondents ranked "Bacteria in food such as $E$-coli or Salmonella" as their number one concern in both tests (mean $=8.96$ and 9.55 , respectively). They were least concerned about electricity-based food irradiation in both tests (mean $=4.61$ and 3.91 , respectively). The respondents' concern for radioactive isotope-based food irradiation decreased in the post-test $($ mean $=\mathbf{5 . 3 5}$ and 4.64, respectively).
KNOWLEDGE OF FOOD IRRADIATION. Respondents assessed their knowledge of food irradiation by answering five multiple-choice questions (Table 4). The correct response rate for each individual question ranged from 21 to 7 in the pre-test and 22 to 15 in the post-test. Some respondents chose not to answer some questions in each test. Most respondents answered the following two questions incorrectly on the pre-test (14), but answered them correctly on the post-test $(18,15)$ :

-Approved doses of food irradiation can destroy bacteria.

-Which is NOT a benefit of food irradiation at approved doses? Makes fresh meat and poultry shelf-stable.

Paired sample t-Tests. Paired samples $t$-tests revealed the short course produced significant knowl-

Table 2. Comparison of participants' $(n=22)$ perceived knowledge and understanding of food safety and food irradiation in the Improving Safety of Complex Food Items Using Electron Beam Technology short course, presented by descending means for the post-test.

\begin{tabular}{|c|c|c|c|c|}
\hline \multirow[b]{2}{*}{ Statements } & \multicolumn{2}{|c|}{ Pre-test } & \multicolumn{2}{|c|}{ Post-test } \\
\hline & Mean $^{\mathrm{z}}$ & SD & Mean $^{z}$ & SD \\
\hline How would you rate your knowledge of food safety? & 3.96 & 0.71 & 4.09 & 0.85 \\
\hline How would you rate your knowledge of food irradiation? & 2.35 & 1.23 & 3.70 & 0.83 \\
\hline
\end{tabular}

${ }^{2}$ Likert-type scale: 1 = poor; 2 = fair; 3 = average; 4 = good; 5 = excellent.

Table 3. Comparison of participants' $(n=22)$ ranking levels of concerns about food safety issues from the pre-test to the post-test results in the Improving Safety of Complex Food Items Using Electron Beam Technology short course, presented by ascending post-test concern levels.

\begin{tabular}{|c|c|c|c|c|c|c|}
\hline \multirow[b]{2}{*}{ Issues } & \multicolumn{3}{|c|}{ Pre-test } & \multicolumn{3}{|c|}{ Post-test } \\
\hline & Mean $^{\mathrm{z}}$ & SD & $\operatorname{Rank}^{\mathrm{y}}$ & Mean $^{\mathrm{z}}$ & SD & $\operatorname{Rank}^{\mathrm{y}}$ \\
\hline Bacteria in food such as E-coli or Salmonella & 8.96 & 1.89 & 1 & 9.55 & 0.86 & 1 \\
\hline Pesticide residues & 7.30 & 2.60 & 2 & 7.14 & 2.75 & 2 \\
\hline Artificial additives & 6.52 & 2.50 & 3 & 6.59 & 2.24 & 3 \\
\hline Hormones in food & 5.91 & 2.52 & 4 & 6.18 & 2.92 & 4 \\
\hline Genetically modified food ingredients & 5.30 & 2.49 & 6 & 5.41 & 2.67 & 5 \\
\hline Radioactive isotope-based food irradiation & 5.35 & 2.55 & 5 & 4.64 & 2.75 & 6 \\
\hline Electricity-based food irradiation & 4.61 & 2.33 & 7 & 3.91 & 2.86 & 7 \\
\hline
\end{tabular}

${ }^{2}$ Rank scale: 1 = no concern; $10=$ high concern.
y Overall rank was determined by weighting raw scores; first-place ranks received one point each, while 10 th-place ranks received 10 points each. Individual weighted scores were summarized to derive the overall rank.

Table 4. Comparison participants' $(n=22)$ pre-test and post-test correct responses to multiple-choice knowledge questions in the Improving Safety of Complex Food Items Using Electron Beam Technology short course.

\begin{tabular}{|c|c|c|c|c|}
\hline \multirow{2}{*}{$\begin{array}{l}\text { Knowledge } \\
\text { questions }\end{array}$} & \multicolumn{2}{|c|}{ Pre-test ${ }^{\mathrm{z}}$} & \multicolumn{2}{|c|}{ Post-test ${ }^{2}$} \\
\hline & Correct & Incorrect & Correct & Incorrect \\
\hline Food irradiation can be an additional food safety processing step. & 21 & 1 & 22 & \\
\hline Approved doses of food irradiation can destroy bacteria. & 7 & 14 & 18 & 4 \\
\hline Which is NOT a benefit of food irradiation at approved doses? & & & & \\
\hline Makes fresh meat and poultry shelf-stable. & 8 & 14 & 15 & 7 \\
\hline
\end{tabular}

${ }^{2}$ Total responses may not equal 22 because of missing answers. 
Table 5. Analysis of paired samples $t$-test for food safety and food irradiation summarized scales $($ with $\mathbf{n}=22)$.

\begin{tabular}{|c|c|c|c|c|c|c|}
\hline \multirow[b]{2}{*}{ Summarized scales } & \multicolumn{2}{|c|}{ Pre-test } & \multicolumn{2}{|c|}{ Post-test } & \multirow[b]{2}{*}{$t$} & \multirow[b]{2}{*}{ Significance } \\
\hline & Mean & SD & Mean & SD & & \\
\hline Food irradiation knowledge & 3.23 & 1.07 & 4.23 & 0.75 & $-4.58 *$ & 0.00 \\
\hline Food safety understanding & 8.41 & 2.89 & 11.55 & 2.26 & -7.01 * & 0.00 \\
\hline Food safety concerns & 43.57 & 14.04 & 43.76 & 13.46 & -0.12 & 0.91 \\
\hline Perceived consumer concerns & 42.14 & 10.15 & 43.14 & 14.09 & -0.37 & 0.72 \\
\hline
\end{tabular}

* Significant at $P<0.05$.

edge gains $[$ mean $=4.26 ; \mathrm{SD}=0.75$ $t(21)=-4.58 ; P<0.05$ (one-tailed)], but the number of incorrectly answered questions in the post-test implies that additional food irradiation training would be beneficial for the respondents.

Respondents' perceptions of food safety and food irradiation issues was improved significantly $[$ mean $=63.39$; $\mathrm{SD}=6.49 ; t(2 \mathrm{l})=-4.17 ; P<0.05$ (onetailed) ] as a result of the short course. Also, their perceived understanding of food safety, food irradiation, and the technology behind food irradiation improved significantly $[$ mean $=11.52$; $\mathrm{SD}=2.21 ; t(21)=-7.01 ; P<0.05$ (one-tailed)] upon completion of the short course (Table 5 ).

No significant changes occurred in respondents' overall levels of concern for food safety issues or perceived consumers' concerns with irradiated foods. Likewise, no significant changes occurred in respondents' agreement levels with the perceived major concerns affecting the adoption of irradiated foods (Table 5 ).

\section{Conclusion}

This short course produced significant knowledge gains in food safety knowledge. Additionally, the short course changed attitudes and perceptions regarding food irradiation. However, the original target audience of vegetable producers and processors was underrepresented in the short course; only $14 \%$ of the individuals invited actually attended the short course. Reasons perceived by the researchers for this lack of attendance were that the 3 - $\mathrm{d}$ short course was too lengthy; the time of year may have been unsuitable; and the perceived likelihood of adopting this technology was so remote that the short course was deemed irrelevant to the invited potential audience. Reasons for this lack of attendance should be examined so that appropriate educational opportunities can be created that will target this audience, which has the potential to influence the food irradiation adoption process.

While food irradiation is a technological concept with a 100 -year history, it has had a slow rate of adoption by food industry professionals and consumers. Rogers (1995) describes the innovation adoption process, or diffusion, as the process of "an innovation being communicated through channels over time among the members of a social system." There are several characteristics of the innovation that help explain an innovation's rate of adoption. Those characteristics are relative advantage, compatibility, complexity, trialability, and observability (Rogers, 1995). This short course set out to clarify some of the aforementioned characteristics of food irradiation so it would be more likely to be adopted by food industry professionals. Those characteristics specifically targeted were trialability, complexity, and observability via experiential education aspects of the short course. Rogers (1995) defines complexity as "the degree to which an innovation is perceived as difficult to understand and use," which was targeted through lectures from experts, group discussion, and the tour of the irradiation facility. Observability is, as defined by Rogers (1995), "the degree to which the results of an innovation are visible to others," which was addressed through group discussion with those who have implemented food irradiation. This allowed the participants an opportunity to ask questions, observe, and understand the results of the innovation from those who have already adopted food irradiation. Rogers (1995) defines trialability as "the degree to which an innovation may be experimented with on a limited basis."
Participants were able to try food irradiation on a small scale by a taste-test comparison of irradiated products to non-irradiated products.

Another explanation for the slow diffusion of food irradiation is the outrage factor. Groth (1991) identifies food irradiation as a low hazard, high outrage risk while microbes in food are a high hazard, low outrage risk. Sandman (1987) defines risk as the sum of hazard and outrage. Outrage refers to the acceptability of a risk that can be influenced by characteristics of the risk, such as familiarity, voluntariness, control, and dread (Sandman, 1987). Groth (1991) explains that scientists need to understand how non-technical citizens understand risks in order to be effective as an educator. Sandman (1987) claims that while the public puts too much emphasis on the outrage side of a risk, experts tend to ignore outrage completely. Bruhn (1994) noted that previous studies demonstrate that once educated, most consumers will buy irradiated foods. She points out that concern for a new technology should not halt the adoption, but accentuate the need for educational programs (Bruhn, 1994). In this short course, common consumer concerns were presented, including many high outrage, low hazard claims made by food irradiation opponents. These concerns were addressed directly and scientifically so that the food industry professional would be able to educate consumers appropriately.

Food irradiation is not a widely adopted technology; however, it is a safe, viable technology for reducing foodborne illness. Research, such as described in this study, has shown that effective educational programs can positively influence a person's knowledge and perceptions of food irradiation. 


\section{Literature cited}

Andress, E.L. 2001. Food irradiation: Historical milestones. Coop. Ext. Serv., Univ. Georgia. Bul. FDNS-E-6.

Ary, D., L. Jacobs, and A. Razavieh. 1996. Introduction to research in education, 5 th ed. Holt, Rinehart, and Winston, Ft. Worth, Texas.

Bruhn, C.M. 1994. Strategies for communicating the facts on food irradiation to consumers. J. Food Protection 58(1):213-216.

Cronbach, L.J. 1951. Coefficient alpha and the internal structure of tests. Psychometrika 16:297-334.

Diehl, J.F. 2002. Food irradiation-Past, present and future. Radiation Phys. Chem. 63:211-215.

Edwards, K. 1990. The interplay of affect and cognition in attitude formation and change. J. Personality Social Psychology 59(2):202-16.

Fazio, R.H., M.C. Powell, and C.J. Williams. 1989. The role of attitude accessibility in the attitude-to-behavior process. J. Consumer Resources 16(3):280-88.

Gall, M.D., J.P. Gall, and W.R. Borg. 2003. Educational research: An introduction, 7th ed. Allyn and Bacon, Boston.
Groth, E.G. 1991. Communicating with consumers about food safety and risk issues. Food Technol. 45(5):248.

Hoban, T.J. 1996. How Japanese consumers view biotechnology. Food Technol. 50:85-88.

Ladner, M.D., G.J. Wingenbach, and M.R. Raven. 2002. Internet and paper based data collection methods in agricultural education research. J. Southern Agr. Educ. Res. 52:40-51. I Aug. 2005. <http://pubs. aged.tamu.edu/jsaer/pdf/Vol52/5202-040.pdf>.

Likert, R. 1932. A technique for the measurement of attitudes. Arch. Psychology 140:1-55.

May, R. 1969. Love and will. Norton, New York.

Mehrens, W.A. and I.J. Lehmann. 1973. Measurement and evaluation in education and psychology, lst ed. Holt, Rinehart and Winston, New York.

National Research Council. 1989. Improving risk communication. Natl. Academy Press, Washington, D.C.

Nunnally, J.C. 1976. Psychometric theory. McGraw Hill, New York.
Park, D. and T.A. Vestal. 2003. Electron beam: 2 lst century food technology. Texas Coop. Ext. and Inst. Food Sci. Eng., Texas Agr. Expt. Sta. SP-157.

Rogers, E.M. 1995. Diffusion of innovations, 4th ed. Free Press, New York.

Sanbonmastsu, D.M. and R.H. Fazio. 1990. The role of attitudes in memorybased decision making. J. Personality Social Psychology 59(4):614-22.

Sandman, P.M. 1987. Risk communication: Facing public outrage. EPA J. $13: 21-22$.

Ten Eyck, T.A. 2002. Food irradiation in the news: The cultural clash of a postharvest technology. Agr. Human Values 19:53-61.

Wingenbach, G.J., T. Vestal, and J. Laminack. 2004. CSREES-USDA: National integrated food safety initiative studyImproving safety of complex food items using electron beam technology. 2 July 2004. <http://www.ag-communicators. org/surveys/FIPCES.asp>.

Zimmerman, L., P. Kendall, M. Stone, and T. Hoban. 1994. Consumer knowledge and concern about biotechnology and food safety. Food Technol. 48(11):71-77. 